\title{
Intervensi Pendidikan Kesehatan tentang Dermatitis Kontak terhadap Peningkatan Pengetahuan pada Pekerja Pencuci Mobil
}

\author{
Anggi Isnani Parinduri ${ }^{1, *}$, Annisa Febriana Siregar ${ }^{2}$

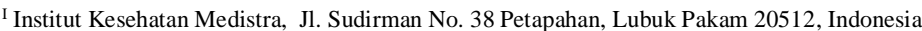 \\ ${ }^{2}$ Institut Kesehatan Medistra, Jl. Sudirman No. 38 Petapahan, Lubuk Pakam 20512, Indonesia \\ ${ }^{1}$ Email: anggisnani@gmail.com *; ${ }^{2}$ Email : nsafbrn@ gmail.com \\ * corresponding author
}

\section{ABSTRACT}

Keywords

Knowledge

Health Education

Car Wash
Occupational disease is an artificial disease or man made disease. Occupational contact dermatitis is one of the most common occupational skin diseases, car wash workers are at risk of getting contact dermatitis because in the long term they have direct contact with chemicals during the work process. The purpose of this study was to determine the effect of health education interventions on contact dermatitis using flip chart media on increasing knowledge of car wash workers. The type of research used is quasi-experimental research with a one group pre-test-post-test design research design. The population of this research is car wash workers who are in Pangkalan Masyhur Village, Medan Johor City Medan, totaling 52 people. by using primary data and secondary data. The data analysis used in this study consisted of univariate and bivariate analyzes. This analysis uses descriptive statistics to describe the frequency distribution of the independent and dependent variables which are presented in tabular form. The bivariate analysis used in this study was the paired sample t-test. The results showed that there were differences in knowledge of car wash workers before and after health education interventions regarding contact dermatitis and health education interventions using flip chart media about contact dermatitis had an effect on increasing knowledge of washing workers. cars in the Pangkalan Masyhur Urban Village, Medan City in 2020.

\section{Pendahuluan}

Era globalisasi menuntut pelaksanaan kesehatan dan keselamatan kerja di setiap tempat kerja, termasuk di sektor informal. Masalah kesehatan kerja juga sudah diatur dalam UndangUndang Nomor 23 Tahun 1992 tentang kesehatan, pada pasal 23 menyatakan bahwa kesehatan kerja diselenggarakan untuk mewujudkan produktivitas kerja yang optimal agar setiap pekerja dapat bekerja secara sehat tanpa membahayakan diri sendiri dan masyarakat sekelilingnya sejalan dengan program perlindungan tenaga kerja. Di berbagai sektor dalam pelaksanaan pekerjaan sehari-hari, pekerja akan terpapar dengan risiko penyakit akibat kerja. Maka untuk itu perlu ditingkatkan upaya promosi dan pencegahan dalam rangka menekan serendah mungkin risiko penyakit yang timbul akibat pekerjaan atau lingkungan kerja.Dalam rangka pembinaan dan peningkatan perilaku kesehatan masyarakat, pendekatan edukasi (pendidikan kesehatan) lebih tepat dibandingkan dengan pendekatan koersi [1].

Kegiatan pendidikan kesehatan adalah pemberian informasi atau pesan kesehatan berupa penyuluhan kesehatan untuk memberikan atau meningkatkan pengetahuan dan sikap seseorang tentang kesehatan melalui teknik praktik belajar atau instruksi dengan tujuan mengubah atau mempengaruhi perilaku manusia baik secara individu, kelompok maupun masyarakat untuk dapat lebih mandiri agar memudahkan terjadinya perilaku sehat. Penyuluhan kesehatan adalah kegiatan pendidikan kesehatan, yang dilakukan dengan menyebarkan pesan, menanamkan keyakinan, 
sehingga masyarakat tidak saja sadar, tahu, dan mengerti, tetapi juga mau dan bisa melakukan suatu anjuran yang ada hubungannya dengan kesehatan.Tujuannya adalah untuk meningkatkan pengetahuan, sehingga terjadi perubahan perilaku dan meningkatkan kepatuhan yang selanjutnya akan meningkatkan kualitas hidup.Personal higiene merupakan suatu tindakan untuk memelihara kebersihan dan kesehatan seseorang untuk kesejahteraan baik fisik maupun psikis.Tujuan dari personal higiene adalah meningkatkan derajat kesehatan, memelihara kebersihan diri, pencegahan penyakit, meningkatkan kepercayaan diri dan menciptakan keindahan. Pada penelitian ini, praktek personal hygiene berfungsi untuk mengurangiatau menghilangkan bahan kimia yang telah kontak dan menempel pada kulit pekerja, sehingga personal hygiene tidak dapat digunakan sebagai upaya pencegahan dermatitis kontak, akan tetapi sebagai upaya pengurangan dampak bahan kimia terhadap dermatitis kontak yang terjadi pada pekerja pencuci mobil.

Penyakit akibat kerja merupakan penyakit yang artifisial atau man made disease.Sebagian orang menyadari bahwa penyakit yang diderita besar kemungkinan disebabkan pekerjaannya, tetapi banyak yang tidak menyadari bahwa pekerjaan yang dilakukannya sehari-hari merupakan penyebab penyakit tertentu.Dalam pelayan kesehatan terdapat beberapa upaya yang dapat dilakukan, salah satunya adalah upaya peningkatan atau promotif.Upaya promotif bertujuan untuk meningkatkan status kesehatan dan kapasitas kerja. Meliputi pendidikan dan penyuluhan kesehatan kerja, Perilaku Hidup Bersih dan Sehat (PHBS), norma sehat di tempat kerja. Penyakit kulit akibat kerja (occupational dermatoses) merupakan salah satu bentuk penyakit akibat kerja, merupakan jenis penyakit akibat kerja terbanyak kedua setelah penyakit musculoskeletal, berjumlah sekitar $22 \%$ dari seluruh penyakit akibat kerja. Sebanyak $90 \%$ penyakit akibat kerja berlokasi di tangan.Dermatitis kontak merupakan 50\% dari semua penyakit akibat kerja terbanyak yang bersifat nonalergi atau iritan. Penelitian surveillance di Amerika menyebutkan bahwa $80 \%$ penyakit kulit akibat kerja adalah dermatitis kontak [2]. Dermatitis kontak adalah dermatitis disebabkan bahan atau substansi yang menempel pada kulit. Dikenal dua jenis dermatitis kontak, yaitu dermatitis kontak iritan yang merupakan respon nonimunologi dan dermatitis kontak alergik yang diakibatkan oleh mekanisme imunologik spesifik. Keduanya dapat bersifat akut maupun kronis dan paling sering disebabkan karena faktor kimiawi [3].

Berdasarkan permasalahan di atas, maka penting dilakukan penelitian mengenai intervensi pendidikan kesehatan tentang dermatitis kontak terhadap peningkatan pengetahuan pada pekerja pencuci mobil di Kelurahan Pangkalan Masyhur Kecamatan Medan Johor Kota Medan Tahun 2020.Pendidikan kesehatan dalam penelitian ini berupa pemberian penyuluhan personal higiene dan penggunaan alat pelindung diri terkait dermatitis kontak dengan menggunakan media flip chart. Hasil penelitian ini dapat menjadi dasar untuk penelitian selanjutnya agar mendapatkan pengetahuan yang lebih luas dalam rangka menyusun perencanaan dan program penanggulangan terhadap pekerja di sektor informal khususnya pada pekerja pencuci mobil yang terkena penyakit akibat kerja yaitu dermatitis kontak.

\section{Metode}

Pada penelitian ini, jenis yang digunakan adalah penelitian eksperimen semu (QuasiExperimental) dengan desain penelitian one group pre test-post test design. Desain penelitian ini diukur menggunakan pre test yang dilakukan sebelum diberi perlakuan yaitu dengan memberikan kuesioner untuk mengetahui pengetahuan sebelum diberikan intervensi, kemudian diberikan intervensi berupapendidikan kesehatan mengenai personal higiene dan penggunaan alat pelindung diri dengan media flip chart, dan post test yang dilakukan setelah diberi perlakuan yaitu dengan memberikan kuesioner pos-test untuk mengetahui pengetahuan setelah diberikan intervensi. Populasi penelitian adalah pekerja pencuci mobil yang berada di Kecamatan Pangkalan Masyhur berjumlah 52 orang.

Pengumpulan data dengan menggunakan data primer dan data sekunder.Wawancara kepada responden dengan berpedoman pada kuesioner yang telah dipersiapkan merupakan teknik yang digunakan dalam mengumpulkan data primer. Sedangkan data sekunder diperoleh.dari kantor Lurah Kelurahan Pangkalan Masyhur Kota Medan. Analisa data yang digunakan dalam penelitian 
ini terdiri dari analisa univariat dan bivariat.Analisis ini menggunakan statistik deskriptif untuk menggambarkan distribusi frekuensi dari variabelindependendan variabeldependen yang disajikan dalam bentuk tabel.Analisi bivariat yang digunakan dalam penelitian ini adalah uji Paired Sample T-test.

\section{Hasil dan Diskusi}

Penelitian ini dilakukan pada pekerja pencuci mobil di Kelurahan Pangkalan Masyhur, merupakan salah satu kelurahan yang berada di Kecamatan Medan Johor Kota Medan. Batas wilayah Kelurahan Pangkalan Masyhur yaitu sebelah.timur berbatasan dengan Kelurahan Titi Kuning, sebelahselatan berbatasan dengan KelurahanGedung Johor, sebelah barat berbatasan dengan KelurahanKwala Bekala,dan sebelah utara berbatasan dengan Kecamatan MedanPolonia. Jumlah penduduk sebanyak 37.299 jiwa dengan jumlah laki-laki 17.626 orang dan perempuan 19.673 orang.

Pekerja pencuci mobil menggunakan bahan kimia dalam setiap pekerjaannya.Dalam setiap melakukan pekerjaannya pekerja tidak menggunakan alat pelindung diri berupa sarung tangan dan alas kaki.Pekerja pencuci mobil berisiko terkena dermatitis kontak dari paparan bahan kimia yang diterimanya setiap bekerja.Selain itu, peluang berisiko terkena penyakit dermatitis kontak semakin besar ditambah dengan pola kebiasaan mencuci tangan yang tidak benar dan menyebabkan bahan kimia masih menempel di tangan dan kaki pekerja.Tempat kerja yang lembab merupakan faktor di tempat kerja yang mendorong timbulnya penyakit kulit.Kontaminan berupa bahan kimia lebih mudah menempel di kulit pada temperatur lingkungan kerja yang lembab [4].
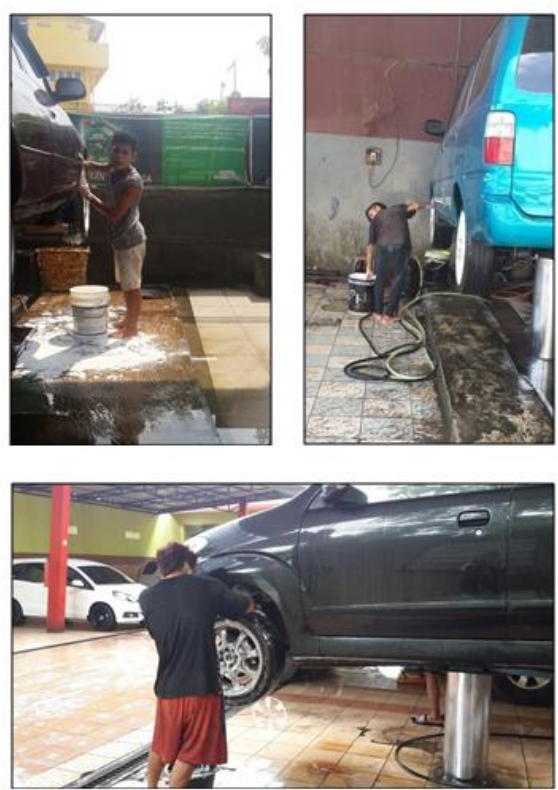

Gambar 1.Pekerja pencuci mobil tidak menggunakan alat pelindung diri 

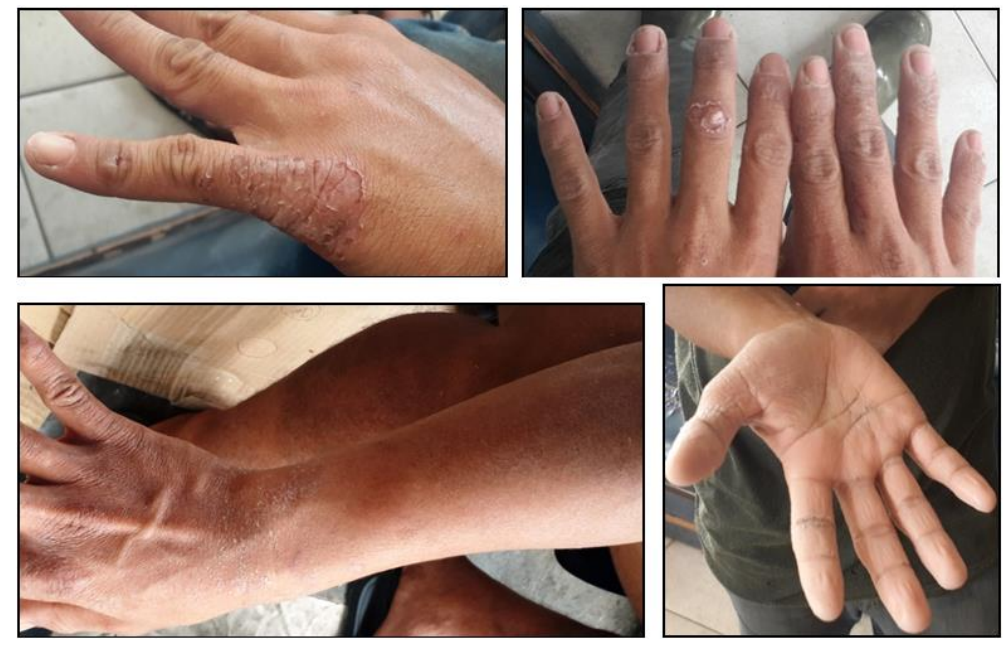

Gambar 2.Dermatitis kontak pada tangan pekerja pencuci mobil
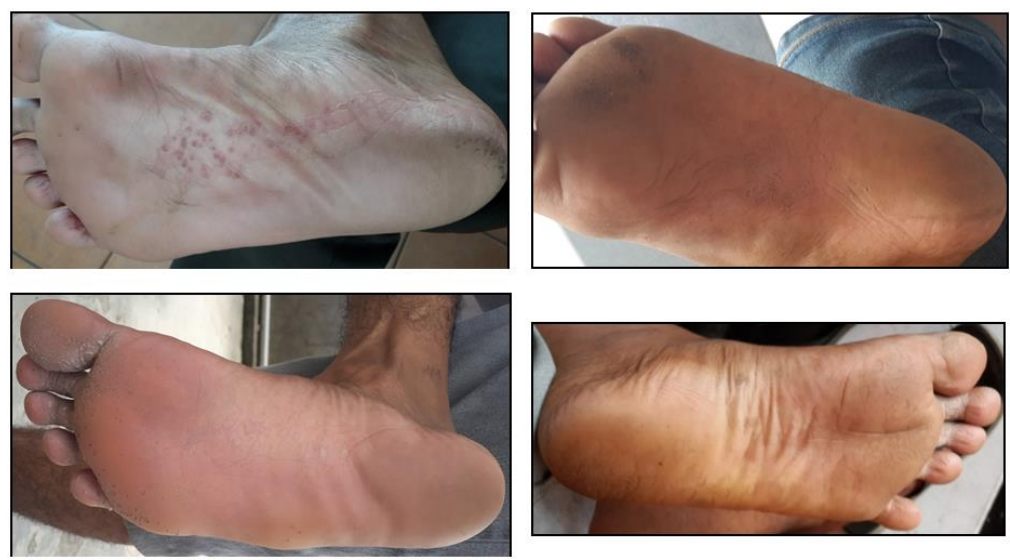

Gambar 3.Dermatitis kontak pada kaki pekerja pencuci mobil .

Hasil wawancara dan observasi yang telah dilakukan oleh peneliti, didapatkan hasil bahwa bahan kimia yang digunakan di tempat pencucian mobil yaitu Texapon (SLS-Sodium Laureth Sulfat) yaitubahandasar sabun atau surfaktan yang berfungsi untuk menurunkanteganganpermukaan air sehinggadapat melepaskan kotoran yang menempel pada permukaan bahan,Sodium Sulfat yaitu pengental sabun berfungsi sebagai penambah kuantitas, STPP (Sodium Tripoly Phosphateyaitu pembersihnoda yang berfungsi untuk meningkatkan daya bersih dan pewarna makanan yang berfungsi sebagai pewarna produk. Bahan-bahan kimia tersebut dapat menyebabkan permukaan kulit kasar, hilangnya kelembabanalami yang ada pada permukankulitdanmeningkatkan permeabilitas permukaan luar,dapat menyebabkan iritasi kulit dan dermatitis, jika kulit sudah teriritasi ditandaidenganmunculbeberapagejala sepertirasagatal,kulit yangmeradang diikutidengan pembentukanlepuhberisi cairan. Individu yang alergi, tentunya lebihrentan mendapatkan efeksamping dimana kulit mereka akan cenderung mengikis lapisan minyak alami kulit sehinggakulit bisa kering, bersisik dan kasar.Faktor lain yang mempermudah DAK yaitu keturunan atau genetik, lingkungan serta faktor tidak langsung seperti umur, pengalaman kerja, pemakaian obat-obat dan stress psiko-sosial. Penyakit kulit yang termasuk DAK yaitu: Dermatitis Kontak, Dermatitis Kontak Iritan dan Dermatitis Kontak Alergika [5]. 
Tabel 1. Distribusi Karakteristik Pekerja Pencuci Mobil

\begin{tabular}{lcc}
\hline \multicolumn{1}{c}{ Karakteristik Pekerja } & f & \% \\
\hline Umur & & \\
$\leq 30$ tahun & 29 & 55,8 \\
$>30$ tahun & 23 & 44,2 \\
\hline Masa Kerja & & \\
$\leq 1$ tahun & 21 & 40,4 \\
$>1$ tahun & 31 & 59,6 \\
\hline Pendidikan Terakhir & & \\
Tidak sekolah & 2 & 3,8 \\
SD & 8 & 15,4 \\
SMP & 15 & 28,8 \\
SMA & 27 & 51,9 \\
\hline Total & $\mathbf{5 2}$ & $\mathbf{1 0 0 , 0}$ \\
\hline
\end{tabular}

Tabel 1 menunjukkan bahwa dari 52 orang pekerja pencuci mobil, mayoritas responden berumur $\leq 30$ tahun sebanyak 29 orang $(55,8 \%)$, memiliki masa kerja $>1$ tahun sebanyak 31 orang $(59,6 \%)$, dan pendidikan terakhir SMA sebanyak 27orang $(51,9 \%)$.Hasil penelitian ini sesuai dengan penelitianyang dilakukan Erliana (2008) yang menjelaskan bahwa semakin lama pekerja bekerja, maka semakin berisikoterhadap terjadinya dermatitis kontak [6].

Tabel 2.Distribusi Pengetahuan Pekerja Pencuci Mobil sebelum Intervensi Pendidikan Kesehatan

\begin{tabular}{lccc}
\hline & Variabel & f & \% \\
\hline Pengetahuan & & & 90,4 \\
Kurang Baik & 5 & 9,6 \\
Baik & $\mathbf{5 2}$ & $\mathbf{1 0 0 , 0}$ \\
\hline Total & &
\end{tabular}

Tabel 2 menunjukkan bahwa dari 52 orang pekerja pencuci mobil, mayoritas responden yang memiliki pengetahuan yang kurang baik mengenai dermatitis kontak berjumlah 47 orang $(90,4 \%)$ sebelum diberikan intervensi pendidikan kesehatan menggunakan media flip chart.

Tabel 3. Distribusi Pengetahuan Pekerja Pencuci Mobil sesudah Intervensi Pendidikan Kesehatan

\begin{tabular}{|c|c|c|}
\hline Variabel & $\mathbf{f}$ & $\%$ \\
\hline $\begin{array}{l}\text { Pengetahuan } \\
\text { Kurang Baik } \\
\text { Baik }\end{array}$ & $\begin{array}{c}4 \\
48\end{array}$ & $\begin{array}{c}7,7 \\
92,3\end{array}$ \\
\hline Total & 52 & 100,0 \\
\hline
\end{tabular}

Tabel 3menunjukkan bahwa dari 52 orang pekerja pencuci mobil, mayoritas responden yang memiliki pengetahuan yang baik mengenai dermatitis kontak berjumlah 48 orang $(92,3 \%)$ sesudah diberikan intervensi pendidikan kesehatan menggunakan media flip chart.Pengetahuan pekerja pencuci mobil meningkat setelah diberikan penyuluhan mengenai personal higiene dan penggunaan alat pelindung diri, karena sebelumnya pekerja belum pernah mengikuti penyuluhan mengenai potensi bahaya dermatitis kontak dan pencegahannya.Sebelum dilakukan intervensi pekerja juga tidak mengetahui mengenai personal higiene diantaranya adalah langkah cuci tangan yang baik dan benar karena sebelumnya tidak ada pelatihan dan tidak ada penyuluhan mengenai langkah cuci tangan yang baik dan benar, sehingga dalam kesehariannya pekerja hanya sekedar mencuci tangan.Pekerja pencuci mobil tidak menggunakan alat pelindung diri karena tidak disediakan oleh pihak tempat pencuci mobil atau pengusaha. 
Tabel 4.Perbandingan Pengetahuan Pekerja Pencuci Mobil sebelum dan sesudah diberikan Intervensi Pendidikan Kesehatan

\begin{tabular}{lccc}
\hline \multicolumn{1}{c}{ Pengetahuan } & Mean & SD & p. value \\
\hline Pre-test & 5,08 & 1,169 & 0,049 \\
Post-test & 8,10 & 1,015 & \\
\hline
\end{tabular}

Tabel 4 menunjukkan bahwa nilai rata-rata pengetahuan sebelum diberikan pendidikan kesehatan yaitu 5,08 dengan standar deviasi sebesar 1,169 sedangkan nilai rata-rata pengetahuan sesudah diberikan pendidikan kesehatan yaitu 8,10 dengan standar deviasi sebesar 1,015. Berdasarkan tabel diatas diketahui bahwa terjadi perubahan nilai rata-rata pengetahuan sebelum intervensi (pre-test) dengan sesudah intervensi (post-test).Hal ini berarti tingkat pengetahuan setelah dilakukan intervensi pendidikan kesehatan mengalami peningkatan.Berdasarkan analisis dengan menggunakan uji paired sample t-test diperoleh nilai $\mathrm{p}=0,049$, dari hasil ini dapat disimpulkan bahwa terdapat pengaruh intervensi pendidikan kesehatan menggunakan media flip chart terhadap peningkatan pengetahuan pekerja pencuci mobil di Kelurahan Pangkalan Masyhur Kota Medan Tahun 2020.

Penyuluhan merupakan hubungan timbal balik antara penyuluh dan klien (perseorangan atau masyarakat), yang didalamnya terdapat kegiatan yang bertujuan merubah perilaku perseorangan atau masyarakat supaya merek tidak saja sadar, tahu dan mengerti tetapi juga mau dan mampu melakukan anjuran yang diberikan. Penyuluhan kesehatan merupakan kegiatan pendidikan yang dilakukan dengan cara menyebarkan pesan, menanamkan keyakinan sehingga masyarakat tidak saja sadar, tahu dan mengerti, tetapi juga mau dan biasa melaksanakan suatu anjuran yang ada hubungannya dengan kesehatan untuk keberlangsungan hidup menjadi lebih baik dan sehat [7].Media flipchart merupakan penyampaian materi melalui lembaran-lembaran kertas yang berisi tulisan, jika isi materi yang disampaikan penyuluh terlewatkan atau ada lembaran yang harus mendapatkan perhatian kembali maka akan diulang kembali oleh penyuluh, sehingga bagi masyarakat, khususnya pekerja yang berpengetahuan rendah dan lambat mencerna informasi, maka penyuluhan dengan media flipchart sangat membantu meningkatkan pengetahuan pekerja.Selain itudapat menarik perhatian pekerja dan dapat menumbuhkan motivasi dan minat, sehingga pekerja lebih paham dan dapat menguasai tujuan penyuluhan.

\section{Kesimpulan}

1. Terdapat perbedaan pengetahuan pekerja pencuci mobil sebelum dan sesudah dilakukan intervensi pendidikan kesehatan mengenai dermatitis kontak pada pekerja pencuci mobil di Kelurahan Pangkalan Masyhur Kota Medan Tahun 2020.

2. Intervensi pendidikan kesehatan menggunakan media flip charttentang dermatitis kontak berpengaruh terhadap peningkatan pengetahuan pekerja pencuci mobil di Kelurahan Pangkalan Masyhur Kota Medan Tahun 2020.

\section{Saran}

Diharapkan kepada Dinas terkait untuk memperhatikan kesehatan dan keselamatan kerja pekerja sektor informal, khususnya pencuci mobil dengan adanya kegiatan penyuluhan kesehatan secara intensif dan berkelanjutan mengenai personal higiene agar terhindar dari gangguan kesehatan seperti penyakit dermatitis kontak.Diharapkan kepada pemilik tempat pencucian mobil menyediakan alat pelindung diri yang sesuai dengan jenis pekerja pencuci mobil berupa sarung tangan karet dan sepatu boot serta fasilitas personal higiene.Diharapkan kepada pekerja lebih memperhatikan perilaku hidup bersih dan sehat dengan cara menjaga kebersihan diri dan selalu menggunakan alat pelindung diri sehingga mengurangi risiko terkena penyakit akibat kerja. 


\section{Referensi}

[1] S. Notoatmodjo, "Promosi Kesehatan Teori dan Aplikasinya," Jakarta: Rineka Cipta, 2010.

[2] Kosasih, A, "Dermatitis akibat kerja. Bagian ilmu penyakit kulit dan kelamin," Jakarta: Fakultas Kedokteran, Universitas Indonesia, 2004, hlm. 159-172.

[3] Djuanda dan Sularsito, Ilmu Penyakit Kulit dan Kelamin, edisi keenam. Jakarta: Badan Penerbit FKUI, 2011.

[4] Budiyanto, C., "Faktor predisposi yang berpengaruh terhadap kejadian dermatitis kontak akibat kerja pada pekerja percetakan, Skripsi. Fakultas Kedokteran, Surakarta: Universitas Sebelas Maret, 2010.

[6] Erliana, "Hubungan karakteristik individu dan penggunaan alat pelindung diri dengan kejadian dermatitis kontak pada pekerja paving block, Tesis. Medan: Universitas Sumatera Utara, 2008.

[7] Machfoed, "Pendidikan kesehatan masyarakat," Yogyakarta: Fitamaya, 2005. 